\title{
Arrangement and planning of developer's activities in the course of construction megaprojects implementation
}

\author{
Alexandr K. Orlov ${ }^{1, *}$ \\ ${ }^{1}$ Moscow State University of Civil Engineering, 129337, Yaroslavskoye shosse, 26, Moscow, Russia
}

\begin{abstract}
The paper deals with the specific features of megaprojects. Problems related to real estate reproduction in the course of construction megaprojects implementation were analyzed. Considering the specifics of construction megaprojects, recommendations for their performance assessment were developed. Issues relating to development arrangement and planning at all management levels (strategic, tactical and operational) were considered. Recommendations provided in this paper can be used for the assessment of megaproject performance and formation of KPIs for the participants of the construction process.
\end{abstract}

\section{Introduction}

Topical issues of management in construction and in the course of construction projects implementation are considered in modern scientific and business literature [1-6]. Considerable attention is paid to specific features of implementation of construction projects in different segments of real estate markets (hotel, retail, office facilities, etc.), to introduction of different innovations in the investment and construction area. At the same time construction megaprojects that are actively implemented in different countries and affect various economic segments require to be separately considered and studied $[7,8]$.

These projects have a number of peculiarities that allow to consider them as individual and important objects of scientific research.

When considering megaprojects as individual objects of research, special mention should go to the following specific features [9-11]:

- High investment value (over 1 bln. USD).

- Long implementation terms (as a rule, 5+ years).

- Considerable expenditures for infrastructure development.

- Engagement of many participants in project implementation (co-investors) and use of different funding models.

- Impact on socio-economic indicators of the city, region or country as a whole.

- State participation in megaprojects implementation: in many cases megaprojects are implemented through public private partnership (PPP) mechanisms [12-15].

*Corresponding author: alor333@gmail.com 
Megaprojects represent integrated target programs [16] that can include subprograms and projects amalgamating interests of several (or many) co-investors and, what is a critical aspect, state interests at different management levels (from federal up to regional and municipal).

One can refer the following programs to megaprojects: programs for the creation of special economic zones, territorial clusters, priority development territories [17], projects for comprehensive development of territories and urban development, implementation of complex infrastructure projects such as construction of toll roads, power facilities, etc. as well as other large-scale projects with the participation of public funding and private capital. Special focus should be placed on global projects, which are implemented with the participation of several countries [18].

When studying development megaprojects, particular attention should be paid to state participation in implementation of such programs. Mechanisms and forms of state participation in such projects can vary significantly, ranging from the creation of a favorable mode of project management up to state participation in project financing.

It should be noted that construction activity is the basic component of megaprojects implementation, an important condition ensuring target programs competitiveness in general and performance of local projects of individual investors.

Conditions for the effective implementation of target programs are created via the process of real estate reproduction in its various forms. Moreover, competitiveness and megaproject performance depend on the performance and quality of reproduction processes within the framework of construction activities at all stages of a megaproject life cycle.

The major difficulties in the course of real estate reproduction within megaprojects are as follows:

- Difficulties related to concept development and substantiation as well as investment assessment of megaprojects under conditions of risk and uncertainty.

- The need to follow the common goal and idea of megaproject implementation at all management levels.

- The need to consider interests of multiple participants of the investment process.

- Technical complexities related to megaprojects implementation (high capital costs, long project implementation periods, often unique engineering solutions, the need for comprehensive development of the territory, etc.).

- Implementation of projects under conditions of increased investment risks.

- Problems related to effective management of facilities at the operation stage under conditions of large-scale comprehensive development.

- Problems related to raising funds for megaprojects.

Modern scientific sources deal with problems of megaprojects $[9,10,19,20]$, risks associated with their implementation [21-23], and issues related to introduction of innovations in the course of megaprojects implementation [24]. They also provide an analysis of cases in various industries [25-30].

At the same time, the issue related to the arrangement and planning of construction activities, including use of development tools as an effective form of project management is urgent. The purpose of this paper is to develop a common approach to the assessment of megaproject performance, as well as recommendations for the arrangement and planning of developer's activities at all levels (strategic, tactical and operational).

\section{Methodology}

Within the framework of this paper, the following methods were used in the course of development of a common approach to the assessment of construction megaproject performance, as well as recommendations for the arrangement and planning of developer's 
activities: a qualitative scientific analysis, comparison and generalization methods within the framework of a literature review; an economic analysis, economic and mathematical methods, optimization models and an expert evaluation method in the course of formation of the integrating indicator of construction megaprojects performance; a strategic analysis and management tools in the course of arrangement and planning of developer's activities.

The following assumptions should be taken into account when developing the approach to the assessment of megaproject performance:

1.Complexity in determining the factor space for the performance analysis at early stages of megaproject implementation and in carrying out a correct quantitative assessment of their impact on the final performance indicator.

2. The need to ensure interrelations at all levels of megaproject planning (strategic, tactical and operational).

3. Feasibility of megaproject decomposition followed by separation of a construction megaproject and, perhaps, individual construction projects within the global target program. It will allow to link megaproject objectives to tasks at the level of construction, which in turn will provide for more efficient arrangement and planning of construction activities.

4. Program development should be considered as the most efficient form of construction arrangement in the course of planning of construction megaprojects implementation.

The complexity in determining the factor space is due to the fact that the total performance of a megaproject depends on many factors that cannot be considered at an early stage of a project (for example, future costs for construction and infrastructure development, if they are assessed at the conceptual stage).

In addition, when determining performance indicators one should take into account requirements of all participants of the investment process: both private capital and the state at different levels of management.

Significant deviations of actual indicators from the planned ones in the course of megaproject implementation, in addition to uncertainty factors and incorrect risk assessment, are also associated with an inefficient system of planning, when global objectives of a megaproject are set in the early stages and due attention to operational and tactical tasks is not paid, i.e. when there is no clear understanding of how these objectives will be achieved.

The construction component within a megaproject plays a significant role, since it is responsible for the creation of the final product. Therefore, within a megaproject one should separately consider the construction megaproject, which includes individual construction projects (Figure 1).

In modern construction, there are different approaches to the implementation of construction projects: a contracting method, a project method and a development approach. The development approach that presupposes an integrated center of investment process management at all stages of the life cycle is the best one as well as in the course of megaproject implementation, because it allows to link megaproject objectives to tasks at all management levels.

Taking into account the prerequisites specified above, a common approach to megaproject performance assessment was formulated. It is the basic foundation for the arrangement and planning of developer's activities. 


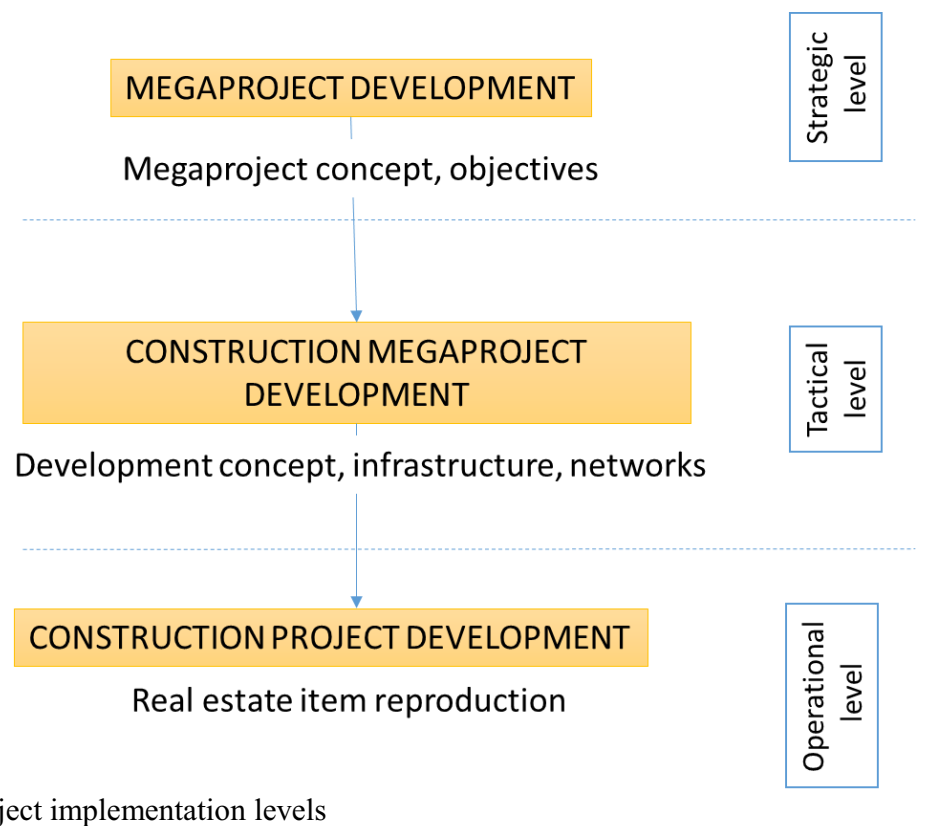

Fig. 1. Megaproject implementation levels

\section{Results}

Within the framework of a megaproject, special mention should go to the following two main components of performance: megaproject performance from the perspective of the state (from now on state interests are also understood to be interests on the regional and local management levels), as well as performance for private capital.

Megaproject performance at the state level $(G)$ is the function of multiple variables like performance for private capital (I). At the same time both the state and private investors strive for the maximization of this performance (1).

$$
\left.\begin{array}{l}
G=f\left(a_{1}, a_{2}, a_{3} \ldots a_{n}\right) \rightarrow \max \\
I=f\left(b_{1}, b_{2}, b_{3} \ldots b_{m}\right) \rightarrow \max
\end{array}\right\}
$$

$a_{1} \ldots a_{n}-$ multiple factors determining performance at the state level.

$\mathrm{b}_{1} \ldots \mathrm{b}_{\mathrm{m}}-$ multiple factors determining performance for private capital.

It should be noted that objectives and tasks at the state and private levels may clash with each other, so the task related to performance maximization is transformed to an optimization task, when there is such a factor combination that can ensure the optimum variant of megaproject implementation that in turn can satisfy all participants.

The list of the most essential factors that will be considered in the optimization model can be developed both on the basis of the financial model of the megaproject and on the basis of expert estimates of the factors that cannot be subjected to qualitative assessment at the conceptual stage of the project.

One can carry out a qualitative assessment of the factors that determine performance for private capital. These are conventional indicators for investment analysis: NPV, IRR, PP, DPP, and PI.

Indicators that reflect achievement of objectives and tasks of the state within the framework of a megaproject depend on the specifics of the project and can include:

- Decline in unemployment, job creation. 
- Increase in GRP and/or GDP.

- Increase in the level of industrial production in the region.

- People's lives improvement (for example, by means of project implementation in the area of housing and utility sector, road infrastructure development, etc.).

- Territorial potential fulfillment (travel, industrial, innovation, etc.).

- Attraction of foreign investments (for example, within the framework of projects for the establishment of special economic zones and priority development areas).

Since it is impossible to determine many of the abovementioned performance indicators in terms of quantity on the basis of the financial model, it is proposed to use expert estimates.

If we use a ten-point scale for the assessment and decline in unemployment is considered as a factor, the expert will give 1 point, if he/she thinks that project implementation will have no effect on this indicator. If the expert thinks that the rate of unemployment will drop down up to the minimum target level specified in the megaproject, he/she will give 10 points.

Space factor determination for performance assessment can be based on Delphi method [31], and assessment of significance of each fact can be based on the analytic hierarchy process.

So, we can expand the abovementioned expressions (1) using a ten-point scale and additive economic and mathematical models in the following way:

$$
\begin{gathered}
\left(G \times k_{1}+I \times k_{2}\right) \geq E_{\min } \\
G=a_{1} \times d_{1}+a_{2} \times d_{2}+a_{3} \times d_{3}+\ldots+a_{n} \times d_{n} \\
I=b_{1} \times d_{1}{ }^{\prime}+b_{2} \times d_{2}{ }^{\prime}+b_{3} \times d_{3}{ }^{\prime}+\ldots+b_{m} \times d_{m}{ }^{\prime}
\end{gathered}
$$

$E_{\min }$ - the lowest estimate of the comprehensive indicator of megaproject performance that allows to the project to be approved for implementation (values of comprehensive indicator $\mathrm{E}$ vary between 0 and 10$)$.

$k_{1}, k_{2}$ - weighted coefficients that reflect the significance of $\mathrm{G}$ and $\mathrm{K}$ respectively, when determining the comprehensive indicator of performance (to be determined by the expert).

$d_{1} \ldots d_{n}$ - weighted coefficients for the factors of performance comprehensive indicator $\mathrm{G}$ (to be determined by the expert).

$d_{1}{ }^{\prime} \ldots d_{m}{ }^{\prime}$ - weighted coefficients for the factors of comprehensive indicator I.

Within the framework of developer's activity planning in the course of construction megaproject implementation it is important to determine key performance indicators (KPI) for the development company of the entire megaproject and individual projects within the framework of the global target program.

Generally the comprehensive indicator of construction megaproject development performance (Dev) can be determined in the following way:

$$
\operatorname{Dev}=f(C, T, Q)=f\left(r_{1}, r_{2} \ldots r_{n}\right)
$$

$C$ - costs for construction project implementation.

$T$ - megaproject implementation period.

$Q$ - qualitative characteristics of a megaproject (compliance with the standards, customer's requirements, etc.). 
$r_{1} \ldots r_{n}-$ assessment of the quality and availability of resources for the implementation of a construction megaproject.

A set of resource includes the following:

- Human resources.

- Raw materials potential of the land and property complex for the purposes of development (location factor, environmental conditions, site characteristics).

- Materials and equipment (vehicles, equipment, machinery, necessary materials, raw materials, etc.).

- Intellectual assets (patents, inventions, branding, goodwill, different forms of innovations).

- Time resources.

- Public resources (creation of favorable conditions for megaproject implementation, direct and indirect control of investment and entrepreneurial activities, tax concessions and remissions, etc.).

- Other resources (depend on the specifics of megaproject implementation).

The need to carry out the analysis of a resource base is associated with the scale of a megaproject and it may result in disproportionality between supply and demand by individual types of resources and megaproject performance degradation both by means of cost supplement and extension of the project implementation period and by means of quality deterioration of finished objects. Based on the above, the algorithm of making a decision on the feasibility of megaproject implementation considering target indicators of project participants and the resource base available for construction can be presented as the algorithm of sequential actions (Fig. 2). Making a positive investment decision at the strategic level is the basis for KPIs formation for the development company at the level of a construction megaproject (tactical level) and individual construction projects within the framework of the global target program (operational level).

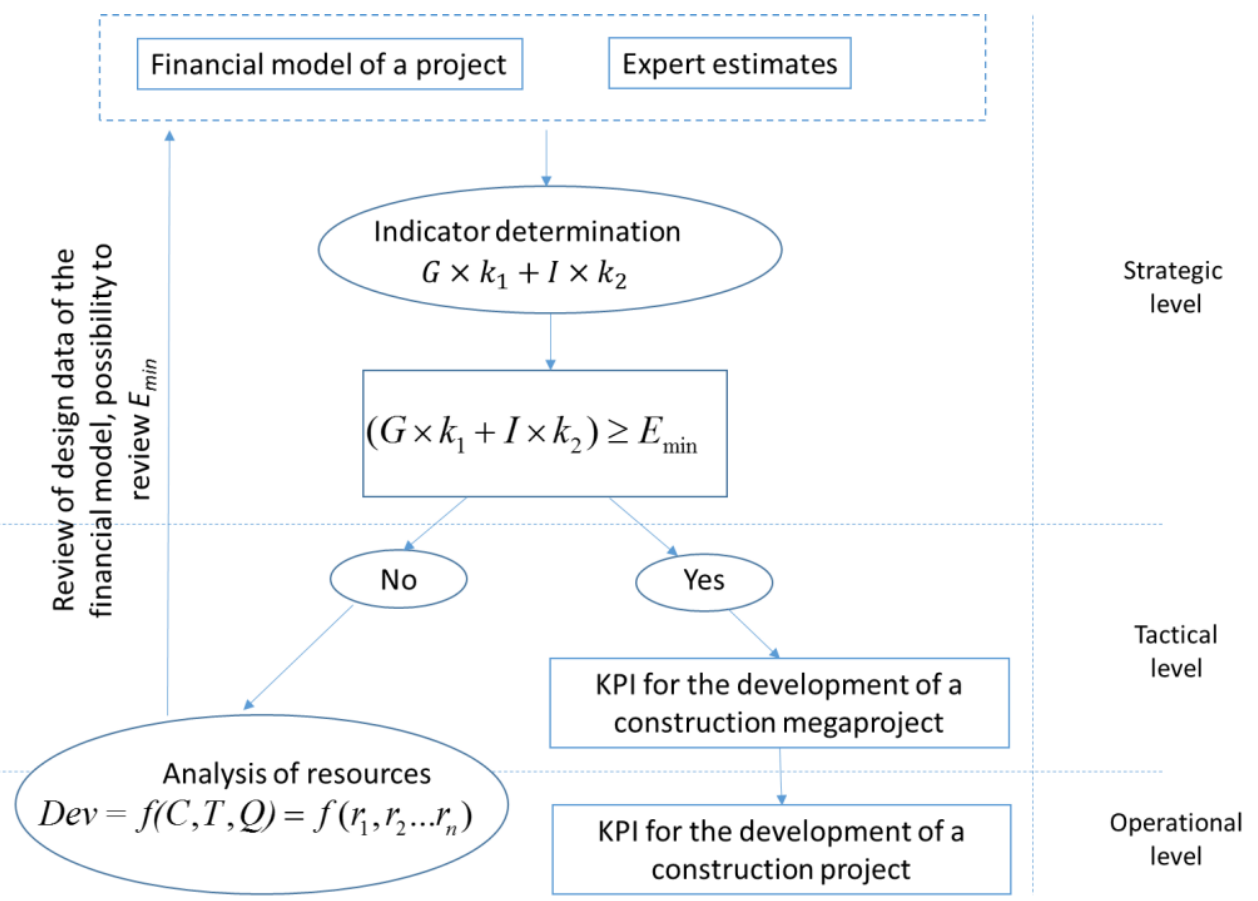

Fig. 2. Megaproject implementation planning at three management levels 


\section{Conclusions}

The mechanism of making investment decisions considering interests of all megaproject participants proposed in this paper is the basis for the arrangement and planning of the development company's activities at the tactical and operational levels. The provisions set forth in this paper require further elaboration, adjustment and practical approval considering the specifics of certain megaprojects.

\section{References}

1. A.P. C. Chan, D. Scot, A.P.L. Chan, Journal of Construction Engineering and Management, 130 (1) (2004)

2. A. Rolstadas, I. Tommelein, P. Morten Schiefloe, G. Ballard, International Journal of Managing Projects in Business, 7(4), 638-660 (2014)

3. F. Harris, R. McCaffer, F. Edum-Fotwe, Modern Construction Management (WileyBlackwell, 2013)

4. R. Peiser, D. Hamilton, Professional real estate development. The ULI guide to the business (Urban Land Institute, 2012)

5. S. Levy, Project Management in Construction (McGraw-Hill Education, 2011)

6. P.G. Grabovy, Real estate economics and management. Manual (Moscow State University of Civil Engineering. Prospectus, 2012]

7. A. Altshuler, D. Luberoff, Mega-Projects: The Changing Politics of Urban Public Investment (Washington, DC: Brookings Institution Press, 2003)

8. Y. Hu, A.P.C Chan, Y. Le, R. Jin, (2015) Journal of Management in Engineering, 31 (4), 4014052 (2015)

9. B. Flyvbjerg, N. Bruzelius, W. Rothengatter, Megaprojects and Risk: An Anatomy of Ambition (Cambridge University Press, 2003)

10. B. Flyvbjerg, Project Management Journal, 45 (2), 6-19 (2014)

11. Y.Zabrodin, A. Mikhailichenko, A. Sarukhanov, V. Shapiro, N. Olderogge, Management of investment programs and project portfolios (Delo ANH, 2010)]

12. R.G. Little, Public Works Management and Policy, 16 (3), 240-249 (2011)

13. A.Van Marrewijk, S.R. Clegg, T.S. Pitsis, M. Veenswijk, International Journal of Project Management, 26 (6), 591-600 (2008)

14. A.K. Orlov, Economics and enterprise, 6 (3), 545-548 (2015)

15. A.K. Orlov, Economics and enterprise, 5 (1), 892-895 (2015)

16. PMBOK Guide. A Guide to the Project Management Body of Knowledge (PMI, 2013)

17. A.K. Orlov, Scientific survey, 14, 315-318 (2015)

18. A. Ainamo, K. Artto, R.E. Levitt, R.J. Orr, W.R. Scott, R. Tainio, Scandinavian Journal of Management, 26 (4), 343-351 (2010)

19. J. Sanderson, International Journal of Project Management, 30 (4), 432-443 (2012)

20. I. Kardes, A. Ozturk, S.T. Cavusgil, E. Cavusgil, International Business Review, 22 (6), 905-917 (2013)

21. P.G. Grabovy, A.K. Orlov, Procedia Engineering, 153, 195-202 (2016)

22. P. Boateng, Z. Chen, S.O. Ogunlana, Megaproject Risk Analysis and Simulation: A Dynamic Systems Approach (Emerald Group Publishing, 2017) 
23. P. Boateng, D. Ahiaga-Dagbui, Z. Chen, S.O. Ogunlana, ARCOM 2015, 115-124 (2015)

24. C. Brockmann, H. Brezinski, A. Erbe, Journal of Construction Engineering and Management, 142 (11), 4016059 (2016)

25. T. Van de Graaf, B.K. Sovacool, Energy Policy, 74 (C), 16-27 (2014)

26. R.F. Callahan, M. Pisano, A. Linder, Public Works Management and Policy, 14 (3), 263-287 (2010)

27. A. Ansar, B. Flyvbjerg, A. Budzier, D. Lunn, Energy Policy, 69, 43-56 (2014)

28. K.R. Molenaar, Journal of Construction Engineering and Management, 131 (3), 343353 (2005)

29. A. Ansar, B. Flyvbjerg, A. Budzier, D. Lunn, Oxford Review of Economic Policy, 32 (3), 360-390 (2016)

30. E.W. Merrow, Industrial Megaprojects: Concepts, Strategies, and Practices for Success (Wiley, 2011)

31. M.R. Hallowell, J.A. Gambatese, Journal of Construction Engineering and Management, 136 (1), 99-107 (2010) 